\title{
Radio Propagation Measurements In Brazil: Clear Air and Rainfall Effects
}

\author{
L.A.R. da Silva Mello, M.S.Pontes, N.R.Dhein and C.M.Einloft \\ Centro de Estudos em Telecomunicações - CETUC \\ Pontifícia Universidade Católica do Rio de Janeiro
}

\begin{abstract}
Methods for the prediction of propagation effect in radio communications systems are usually semiempirical and dependent on the statistical behaviour of radiometeorological parameters, such as refractivity gradient and rainfall rate. The data basis currently available for the devclopment, tcsting and application of these methods have been obtained, mostly, on experiments performed at sites in temperate climates. In the last 15 years scveral propagation measurements' campaigns have been carried out in Brazil, aiming 10 provide data for the development and application of prediction methods in tropical and equatorial climates. In this paper, results from these experiments are reviewed and new data made available in experiments now underway are presented.
\end{abstract}

\section{Introduction}

The design of radio communication systems requires the use of methods for the prediction of propagation effects. These methods are usually semi-empirical, developed and applied based on radiometeorological data. As one example, the prediction of rain induced attenuation, which is the major impairment in the operation of terrestrial and satellite radio links in frequencies above $10 \mathrm{GHz}$, is based on the statistical distribution of rainfall rate at the site of the link. Also, in clear air conditions, the knowledge of the spatial behaviour of the refractivity in the lower troposphere is an essential information for the design of UHF and SHF radio links, as well as for the evaluation of interference between terrestrial communication systems.

For temperate climates, a large amount of information on the statistical behaviour radiometeorological parameters exists. For tropical and equatorial regions, in contrast, very scarce data are available. Propagation predictions commonly show poor accuracy in these regions for two reasons: the available methods were developed based on data obtained in temperate climates and there is no reliable information on meteorological parameters to be used as input for the methods.

Aiming to provide data for the development and application of prediction methods in tropical and equatorial climates several propagation measurements' campaigns have been implemented in Brazil in the last 15 years. The experiments include measurements of point rainfall rate, rain attenuation in terrestrial links, slant path attenuation, refractivity gradient and single frequency fading in line-of-sight links. 


\section{Point Rainfall Rate Measurements}

The cumulative distribution of point rainfall rate is the input for most rain attenuation prediction methods. The most commonly used method, currently recommended [1] by the Intemational Telecommunications Union - Radiocommunications Sector (ITU-R), is based on the assumption that the rain attenuation exceeded at $0.01 \%$ of time is a function of the rainfall rate exceeded at the same time percentage $\left(\mathrm{R}_{0.01}\right)$ and the link geometry. The complete cumulative distribution of rain attenuation is obtained by converting the attenuation value calculated for $0.01 \%$ of time to other time percentages using an empirical expression.

Long term measurements of point rainfall rate were performed at 9 sites in Brazil, shown in Figure 1, using tipping bucket raingauges. The data were analysed with one minute integration time to provide yearly cumulative distributions. The periods of measurements, the location of the sites and the measured values of the parameter $R_{0.01}$ are shown in Table 1 . Also shown, are the values of $R_{0.01}$ recommended by the ITU-R [2] for the regions where the sites are located.

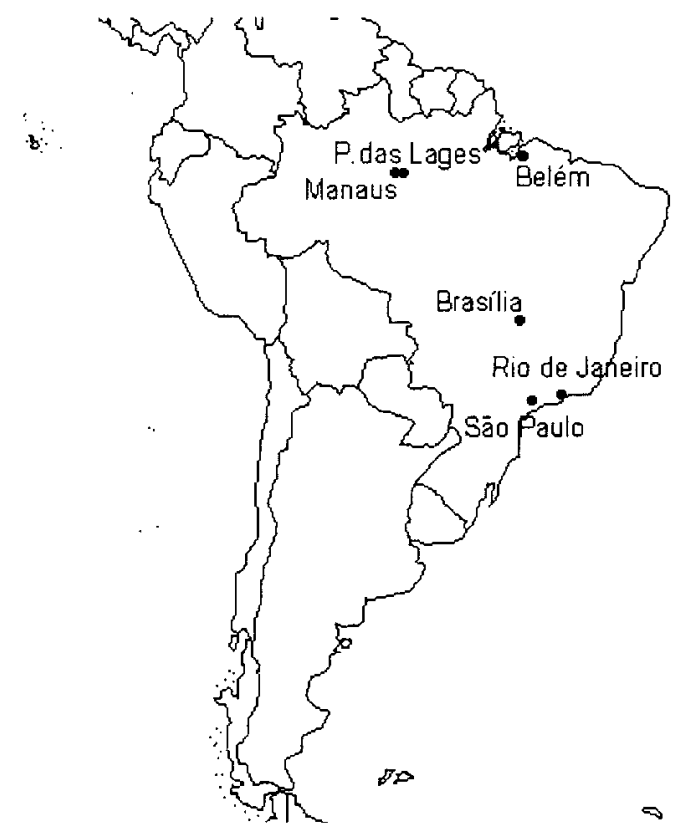

Figure 1 - Rainfall rate measurements sites 


\begin{tabular}{l|c|c|c|c|c}
\hline \multicolumn{1}{c|}{ Site } & Latitude & Longitude & Period & $\begin{array}{c}\mathrm{R}_{0.01} \\
\text { (measured) }\end{array}$ & $\begin{array}{c}\mathrm{R}_{0.01} \\
\text { (ITU-R) }\end{array}$ \\
\hline P.Alegre & $30^{\circ} 02^{\prime} \mathrm{S}$ & $51^{\circ} 13^{\prime} \mathrm{W}$ & Jan84-Jan86 & 90 & 95 \\
\hline Gov.Valadares & $18^{\circ} 51^{\prime} \mathrm{S}$ & $41^{\circ} 56^{\prime} \mathrm{W}$ & Feb84-Feb86 & 65 & 95 \\
\hline Fortaleza & $03^{\circ} 46^{\prime} \mathrm{S}$ & $38^{\circ} 33^{\prime} \mathrm{W}$ & Apr85-Apr86 & 82.3 & 95 \\
\hline Rio de Janeiro & $22^{\circ} 55^{\prime} \mathrm{S}$ & $43^{\circ} 30^{\prime} \mathrm{W}$ & $\begin{array}{c}\text { Dec87-Aug89 } \\
\text { Jan91-Dec92 }\end{array}$ & 82.6 & 95 \\
\hline Belém & $01^{\circ} 27^{\prime} \mathrm{S}$ & $48^{\circ} 29^{\prime} \mathrm{W}$ & Dec87-Nov89 & 124.3 & 145 \\
\hline Manaus & $03^{\circ} 09^{\prime} \mathrm{S}$ & $60^{\circ} 01^{\prime} \mathrm{W}$ & Dec87-Nov89 & 109.3 & 145 \\
\hline $\begin{array}{l}\text { Pta. das Lages } \\
- \text { São Paulo }\end{array}$ & $03^{\circ} 06^{\prime} \mathrm{S}$ & $59^{\circ} 54^{\prime} \mathrm{W}$ & Dec88-Nov89 & 104.8 & 145 \\
\hline Brasília & $15^{\circ} 48^{\prime} \mathrm{S}$ & $47^{\circ} 50^{\prime} \mathrm{W}$ & Jan91-Dec92 & 82.9 & 95 \\
\hline
\end{tabular}

Table 1- Rainfall rate measurements

The average cumulative distributions of point rainfall rate measured are shown in Figure 2, for the sites in ITU-R climatic region N, and Figure 3, for the sites in region $P$. It can be observed that the ITU-R recommended distributions overestimate the measured distributions for all sites.

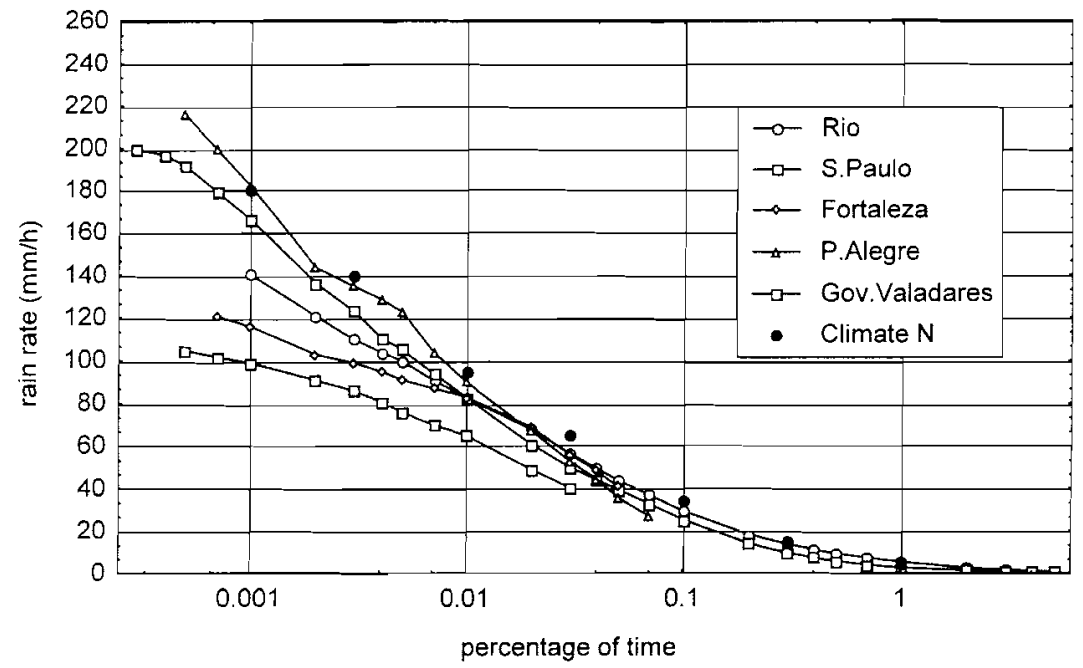

Figure 2 - Rainfall rate distributions: sites in ITU-R climate $N$ 


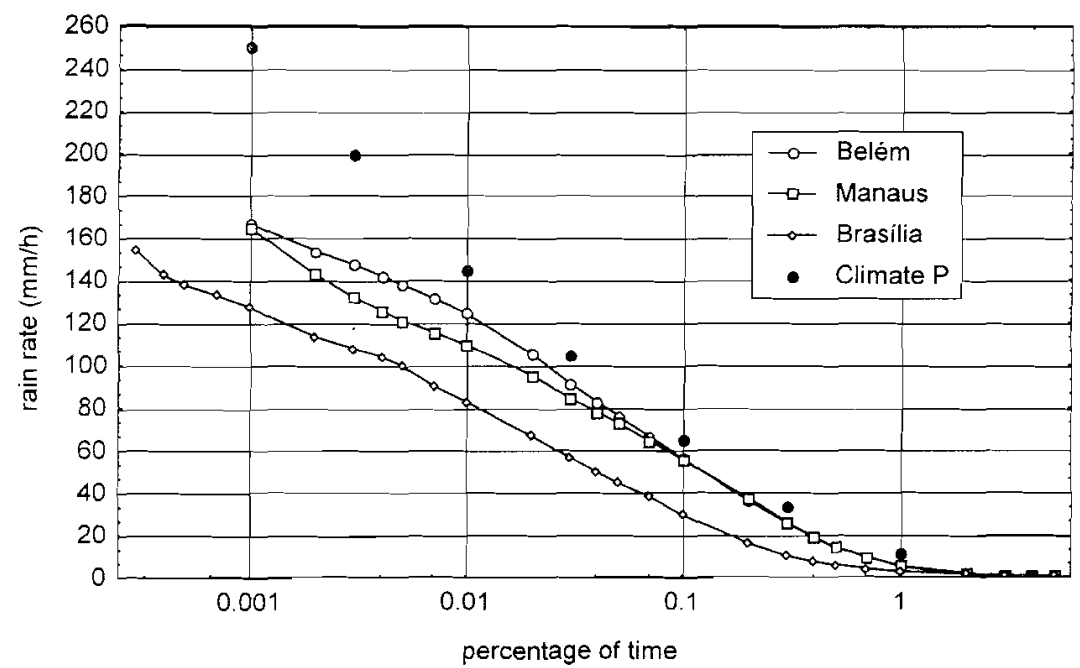

Figure 3 - Rainfall rate distributions: sites in ITU-R climate $P$

The use of ITU-R climate's rain distributions will thus provide conservative estimates of attenuation. Although it can be viewed as an advantage, considering the significant year to year variations of rainfall regimes, the overestimation of the predicted attenuation may be excessive for some sites where the differences between the measured and recommended distributions of rainfall rate is particularly large.

This problem is illustrated in Figures 4 and 5, that show, for Brasília and Gov.Valadares respectively, the maximum path length for a line-of-sight radio link as a function of operation frequency, considering the recommended and measured values of $R_{0.01}$. A systems' flat fading margin of $40 \mathrm{~dB}$ and a maximum outage probability of $0.01 \%$ of time in the worst month have been assumed. The ITU-R rain attenuation prediction method has been used in the calculations. 


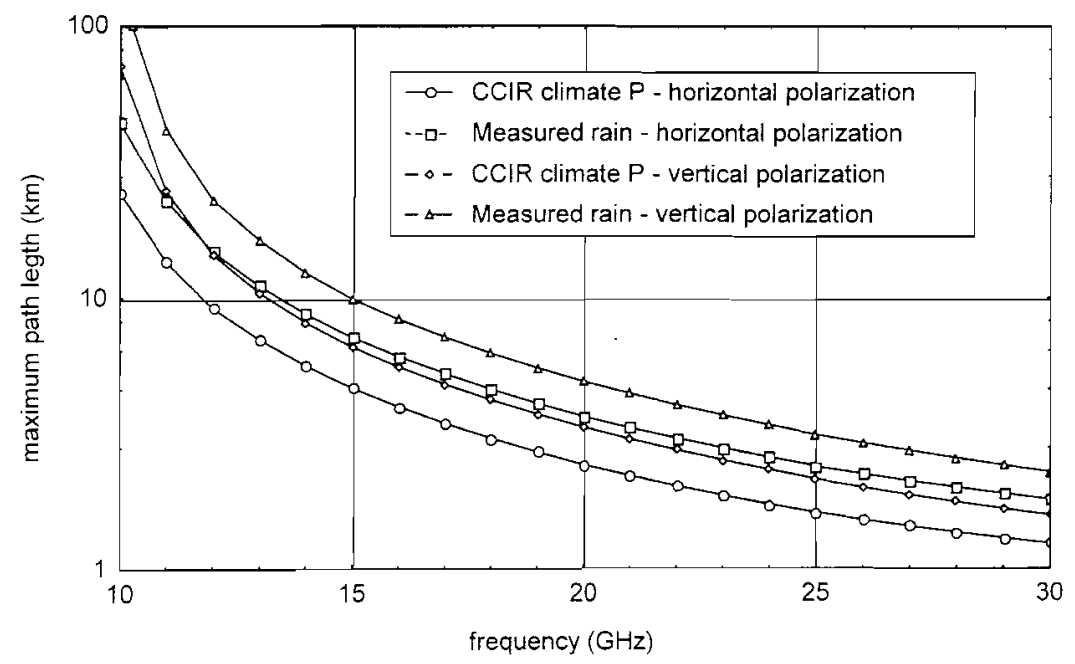

Figure 4 - Maximum path length due to rain attenuation: Brasilia

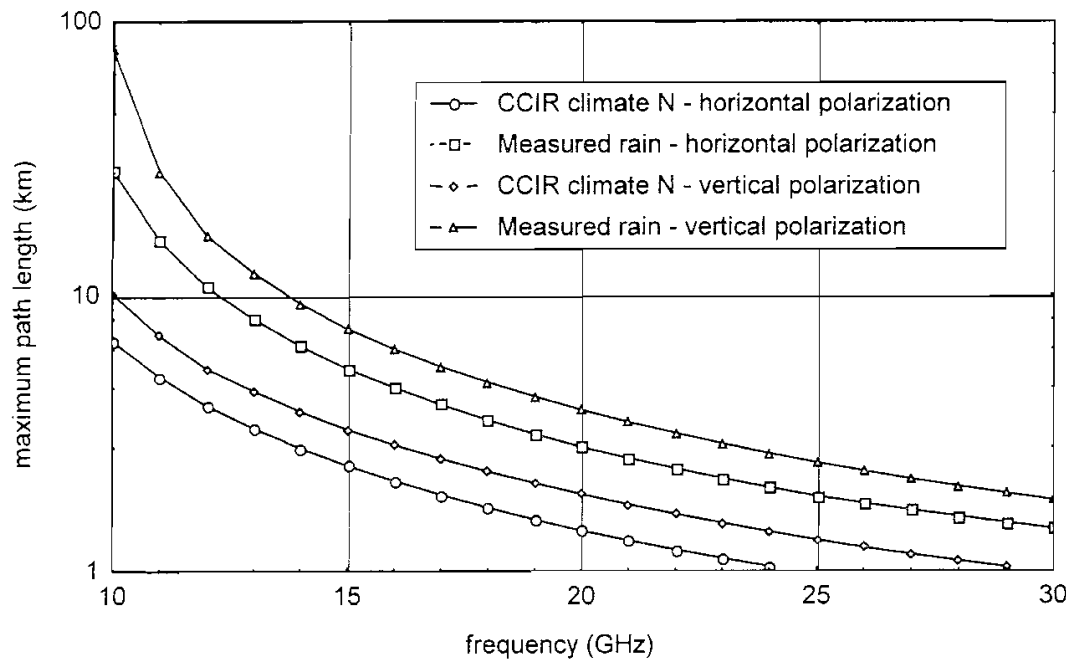

Figure 5 - Maximum path length due to rain attenuation: Gov.Valadares

\section{Measurements Of Rain Attenuation In Terrestrial Paths}

Concurrent measurements of rain attenuation and point rainfall rate were performed in 4 microwave links operating at frequencies above $10 \mathrm{GHz}$.. The location of the 
measurement sites, links' characteristics and periods of measurements are shown in Table 2.

\begin{tabular}{l|c|c|c|c|c}
\hline \multicolumn{1}{c|}{ Site } & Frequency & Latitude & Longitude & Path length & Period \\
\hline S. Paulo & $14.5 \mathrm{GHz}$ & $15^{\circ} 48^{\prime} \mathrm{S}$ & $47^{\circ} 50^{\prime} \mathrm{W}$ & $\begin{array}{l}13.5 \mathrm{~km} \\
12.8 \mathrm{~km}\end{array}$ & $\begin{array}{l}\text { Jan92-Dec93 } \\
\text { Jan92-Dec93 }\end{array}$ \\
\hline Fortaleza & $11.0 \mathrm{GHz}$ & $03^{\circ} 46^{\prime} \mathrm{S}$ & $38^{\circ} 33^{\prime} \mathrm{W}$ & $14.2 \mathrm{~km}$ & Apr85-Apr86 \\
\hline Gov.Valadares & $10.8 \mathrm{GHz}$ & $18^{\circ} 51^{\prime} \mathrm{S}$ & $41^{\circ} 56^{\prime} \mathrm{W}$ & $16.2 \mathrm{~km}$ & Feb84-Feb86 \\
\hline P.Alegre & $11.4 \mathrm{GHz}$ & $30^{\circ} 02^{\prime} \mathrm{S}$ & $51^{\circ} 13^{\prime} \mathrm{W}$ & $6.9 \mathrm{~km}$ & Jan84-Jan86 \\
\hline
\end{tabular}

Table 2 - Measurements of rainfall attenuation in terrestrial links

Figure 6 shows the measured cumulative distributions of rain attenuation and rainfall rate and the predicted attenuation distribution (using the ITLT-R method) for S. Paulo.

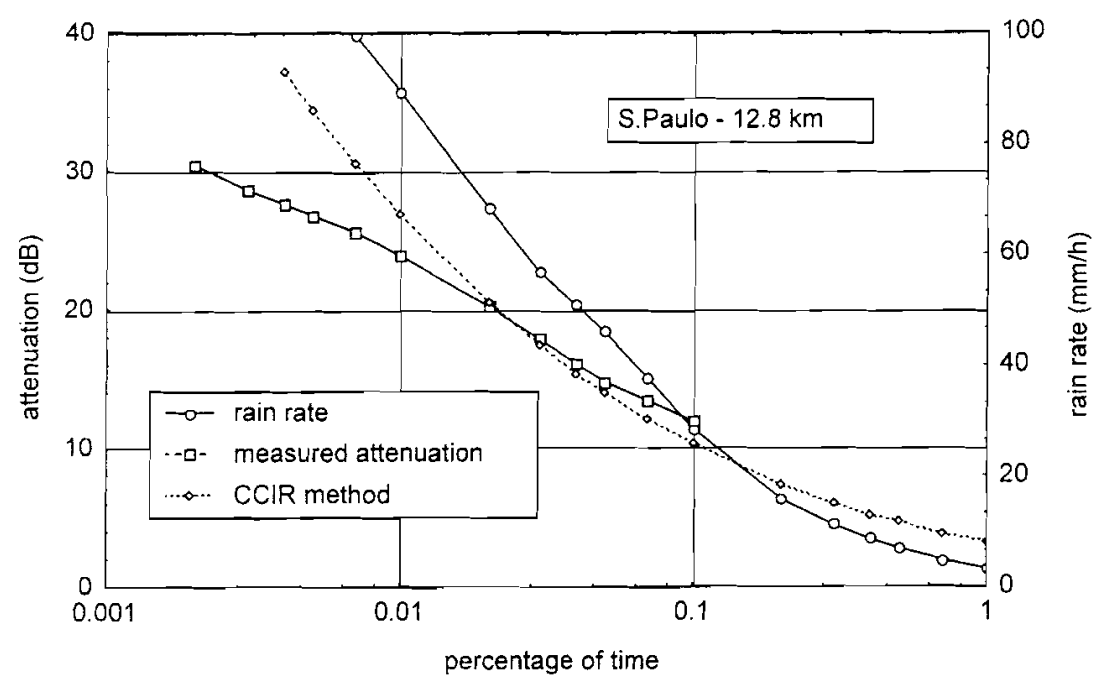

Figure 6 - Cumulative distributions of rain attenuation and rain rate: S. Paulo

The same types of distributions, for the first year of measurements in P. Alegre, are shown in Figure 7. 


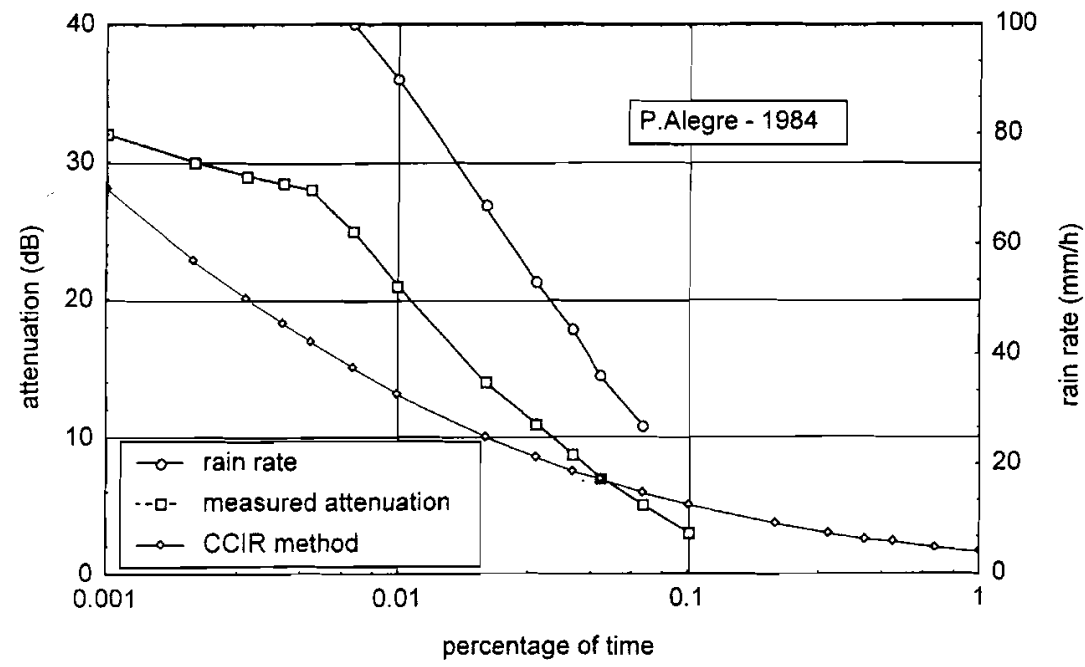

Figure 7 - Cumulative distributions of rain attenuation and rain rate: P.Alegre

Reasonable agreement between the measured and predicted attenuation distributions was observed at S. Paulo and Fortaleza. For P.Alegre and Gov. Valadares, however, the ITU-R method predictions largely underestimate the attenuation at low percentages of time.

The results of these measurements, as well as tests of other prediction techniques available in the literature indicate that more accurate methods for the prediction of rain attenuation in tropical and equatorial climates must be developed. Unfortunately, the data base to support this development is very small, at the moment. A new experiment has started in February 1994 in S. Paulo, with measurements in 8 links of path lengths between 8 and $40 \mathrm{~km}$ and frequencies between 15 and $18 \mathrm{GHz}$, the results of which shall contribute to improve this situation.

\section{Radiometric Measurements Of Rain Attenuation In Slant Paths}

A Ku-band radiometric experiment was initiated in Brazil by the end of 1987, as part of a research program intending to provide a better understanding of slant path rain attenuation behaviour in tropical and equatorial. regions. The complete experiment, with a proposed duration of ten years, is intended to provide propagation data for a one to three-year period, from up to ten sites. The present status of the measurements program is as follows: (a) four sites were covered during a two-year period; (b) one site was covered for a four-year period; (c) a site-diversity configuration was implemented at one of the locations providing one year of data; (d) at one site, a second radiometer is pointed vertically upwards, to characterise the effective rain height (two 
years of data are available); (e) six more sites are to be covered, with radiomete together with beacon receivers, during the next three-year period.

Each measurement system includes a dual-slope radiometer, operating at $12 \mathrm{GHz}$, indoor unit and a tipping-bucket raingauge. The geographical coordinates of $t$ measurement sites from which results are already available are given in Table together with heights above mean sea level, antenna elevations and azimuth angles.

\begin{tabular}{l|c|c|c|c|c}
\hline \multicolumn{1}{c|}{ Site } & Altitude & Latitude & Longitude & Elevation & Period \\
\hline Rio de Janeiro & $30 \mathrm{~m}$ & $22^{\circ} 55^{\prime} \mathrm{S}$ & $43^{\circ} 30^{\prime} \mathrm{W}$ & $53^{\circ} 52^{\prime}$ & $\begin{array}{r}\text { Dec87-Aug8 } \\
\text { Jan91-Dec93 }\end{array}$ \\
\hline Belém & $24 \mathrm{~m}$ & $01^{\circ} 27^{\prime} \mathrm{S}$ & $48^{\circ} 29^{\prime} \mathrm{W}$ & $70^{\circ} 32^{\prime}$ & Dec87-Nov8s \\
\hline Manaus & $48 \mathrm{~m}$ & $03^{\circ} 09^{\prime} \mathrm{S}$ & $60^{\circ} 01^{\prime} \mathrm{W}$ & $83^{\circ} 05^{\prime}$ & Dec87-Nov8 \\
\hline Ponta das Lages & $13 \mathrm{~m}$ & $03^{\circ} 06^{\prime} \mathrm{S}$ & $59^{\circ} 54^{\prime} \mathrm{W}$ & $82^{\circ} 58^{\prime}$ & Dec88-Nov8؛ \\
\hline Brasília & $11^{\circ} 72 \mathrm{~m}$ & $15^{\circ} 48^{\prime} \mathrm{S}$ & $47^{\circ} 50^{\prime} \mathrm{W}$ & $62^{\circ} 53^{\prime}$ & Jan91-Jan93 \\
\hline São Paulo & $760 \mathrm{~m}$ & $23^{\circ} 32^{\prime} \mathrm{S}$ & $46^{\circ} 37^{\prime} \mathrm{W}$ & $52^{\circ} 34^{\prime}$ & Jan91-Apr93 \\
\hline
\end{tabular}

Table 3 - Measurements of rainfall attenuation in slant paths

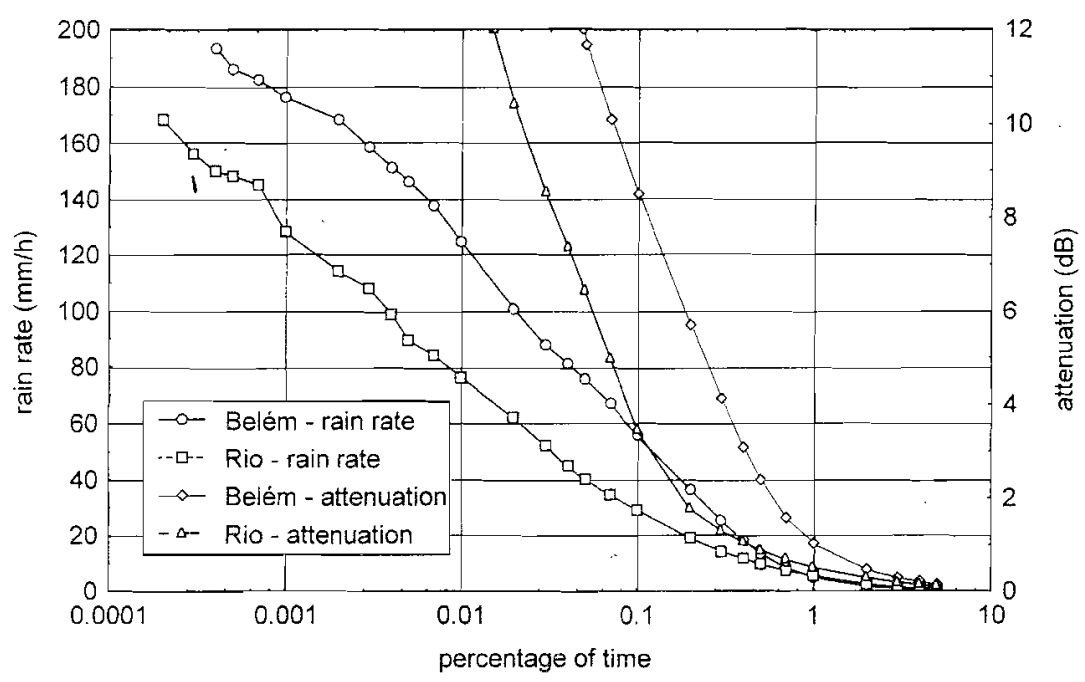

Figure 8 - Cumulative distributions of rain rate and slant path attenuation

The cumulative probability distributions of point rainfall rate and slant path attenuatic were obtained for each measurement site, both in monthly and yearly basis. Year! 
distributions from Belém, in the equatorial region of Brazil, and Rio de Janeiro, in the tropical region, are shown in Figure 8.

In late 1988, site-diversity measurements[3] started in the region of Manaus, on the left bank of the Amazon river. One set of equipment was installed in downtown Manaus and the other was placed at a distance of $13 \mathrm{~km}$, in the station of Ponta das Lages. Both radiometers were pointed towards the orbital position of the Brazilian Satellite at $65^{\circ}$ $\mathrm{W}$, with an elevation angle of $83^{\circ}$. The single sites cumulative distributions of rain rate and equivalent attenuation obtained for Manaus and Ponta das Lages are shown in Figure 9, together with the attenuation distribution observed in site-diversity configuration. The measured diversity gain is in very good agreement with predictions obtained with the Hodge model[4].

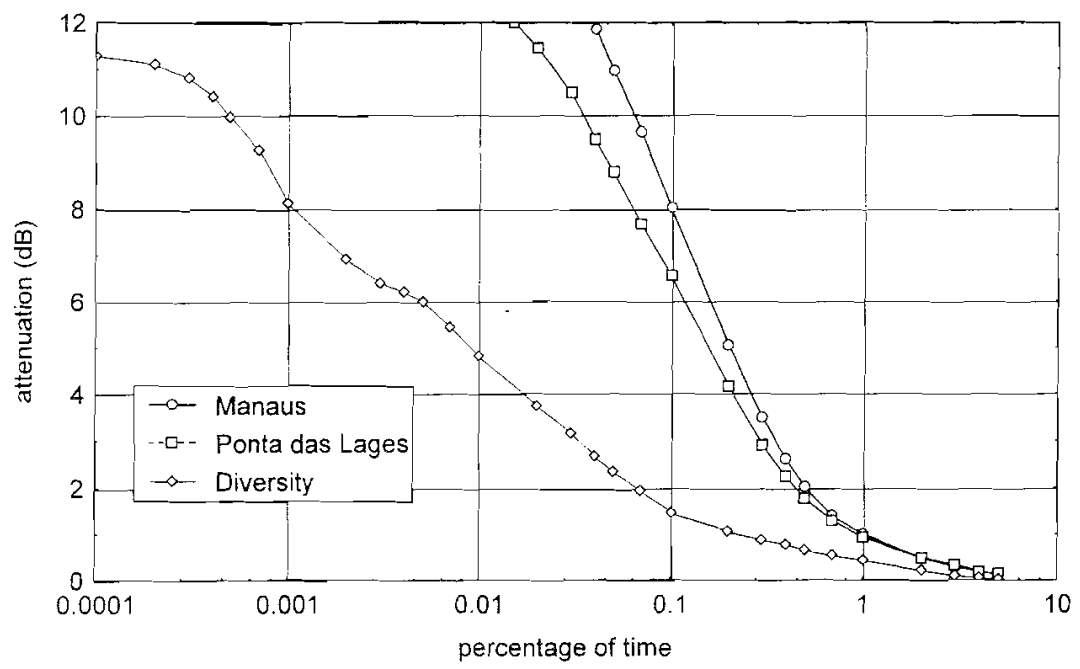

Figure 9 - Single site and site diversity attenuation distributions

In the analysis of fade durations, two conditional distributions were considered: (a) the number distribution of fade durations, $\operatorname{Pn}(\mathrm{D} / \mathrm{A})$, which gives the percentage of the total number of fade events above the attenuation threshold $A$ that have durations exceeding $\mathrm{D}$; (b) the time distribution of fade durations, $\mathrm{Pt}(\mathrm{D} / \mathrm{A})$, which gives the percentage of the total time the attenuation threshold $\mathrm{A}$ is exceeded that is due to fades with durations exceeding $\mathrm{D}$.

To illustrate the procedure used to obtain such distributions, histograms of number of fading events with durations in different class intervals, for attenuation thresholds between $2 \mathrm{~dB}$ and $10 \mathrm{~dB}$, obtained from one year measurements at Manaus, are shown in Figure 10. Integration of each of these histograms produces a number distribution Pn(D/A). Similarly, histograms of total time of fading events can be built and integrated to produce time distributions $\operatorname{Pt}(\mathrm{D} / \mathrm{A})$. 


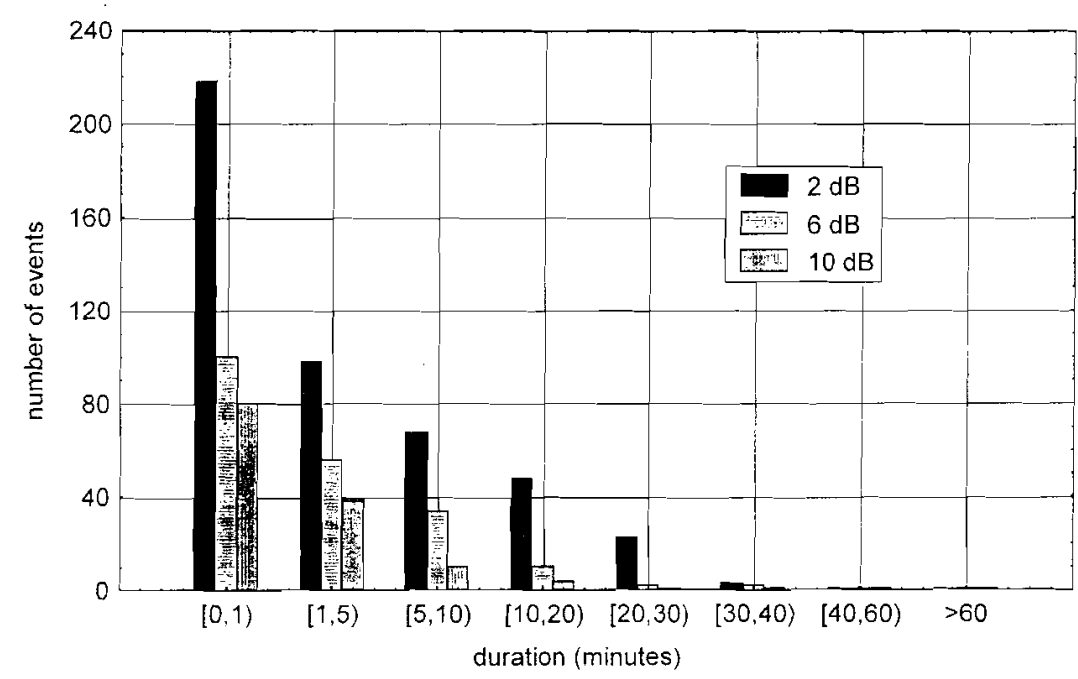

Figure 10 - Histograms of number of fades

Number distributions thus obtained are shown in Figure 11. In these graphs, the effect of site-diversity in fade durations can be observed. For single-site reception, around $5 \%$ of the events of fades above $8 \mathrm{~dB}$, had durations longer than 10 minutes. In site-diversity configuration, no fades above $4 \mathrm{~dB}$ with durations exceeding 10 minutes were observed.

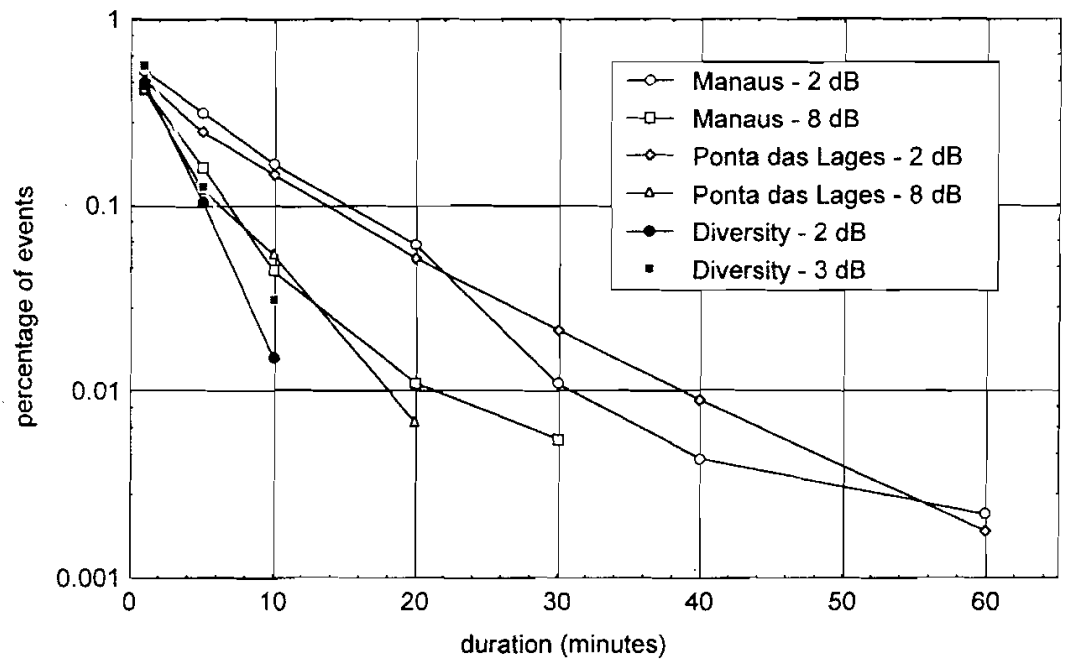

Figure 11 - Number distributions of fade durations 


\section{Refractivity Gradient Measurements}

The knowledge of the refractive index ( $n$ ) of the troposphere is an essential information for the modelling of radiowaves propagation. In practical applications, the refractivity defined as $N=(n-1) \times 10^{-6}$, is used.

The refractivity at a point in the troposphere is a function of the atmospheric pressure ( $p$ mbar), the temperature and the partial pressure of water vapour. It varies primarily with height and its behaviour is usually characterised by the vertical gradient $\frac{\Delta N}{\Delta H}$. For engineering applications, an equivalent earth's radius is defined as $a_{e q}=K \cdot a$, where $a$ is the radius of the earth and the earth's' $\mathrm{K}$ factor is given by

$$
K=\frac{1}{1+a \frac{\Delta N}{\Delta H} \times 10^{-6}}
$$

The median value of $\mathrm{K}\left(K_{\text {med }}\right)$ and the value exceeded during. $99.9 \%$ of the time $\left(K_{\min }\right)$ are used in the design of UHF and SHF radio links.

Statistics of refractivity gradient can be obtained using radio sonde data. Radio sondes are used by meteorological services for measurements of temperature, relative humidity and atmospheric pressure at different heights in the troposphere. A disadvantage of this method is that the radio sonde launches occur only once a day, so that the data are biased. On the other hand, these are routine measurements, so that many years of data are usually available.

Results of radio sonde measurements at thirteen sites in Brazil, for periods between three and eight years, have been analysed to provide statistics of the refractivity gradient. Average year cumulative distributions were obtained from data of eight sites. For the remaining five sites, average distributions for the months of February, May, August and November are available. The sites' locations are illustrated in Figure 13. Also, two-cavity refractometers[5] were used for periods of one year at seven sites to provide continuous measurements of the vertical gradient of refractivity. The sites' locations of the refractometer measurements are also shown in Figure 13. 


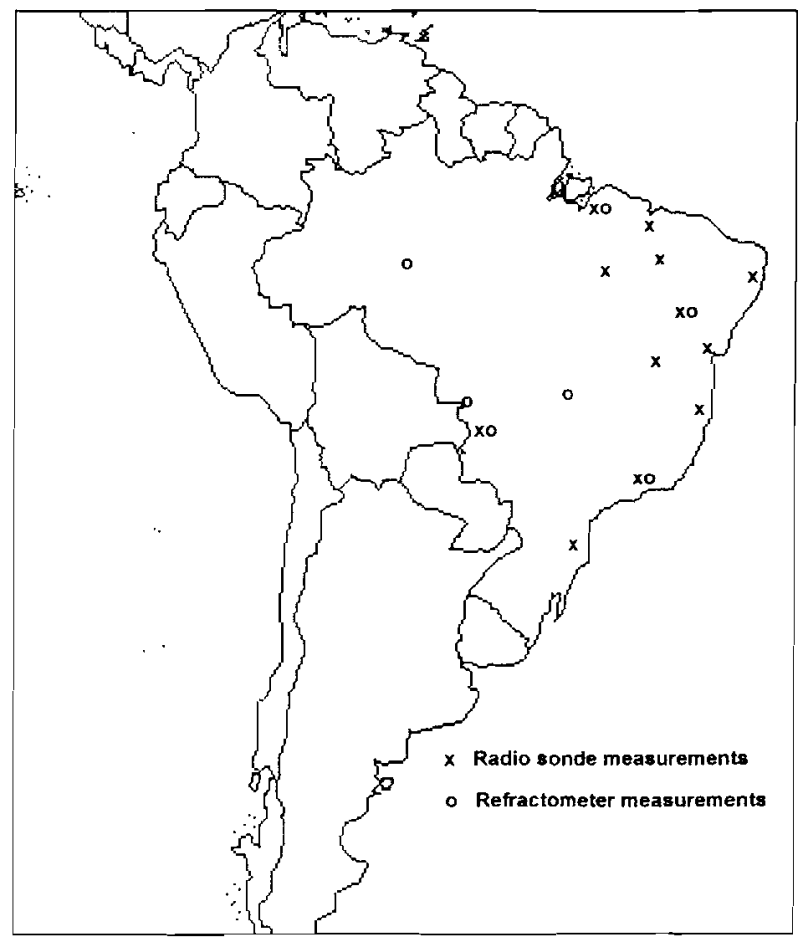

Figure 13 - Refractivity gradient measurements

The measured radio sonde and refractometer data were analysed to provide statistical distributions of the refractivity gradient. The minimum and median values of the earth's K factor were obtained from these distributions.

The median value ( $\left.K_{m e d}\right)$ and minimum value $\left(K_{m i n}\right)$ of the earth's K factor, obtained from the measured distributions are shown in Table 4 . In all cases $K_{m e d}$ is higher than $4 / 3$, value usually adopted for temperate climates. At four sites, radio sonde and refractometer data are available. With the exception of Belém, the values derived from refractometer measurements are higher than those obtained with radio sondes. 


\begin{tabular}{|c|c|c|c|c|}
\hline$\#$ & Site & Measurement & $K_{\text {med }}$ & $K_{\text {min }}$ \\
\hline 1 & Caravelas & Radio sonde & 1.6 & 1.2 \\
\hline 2 & Salvador & Radio sonde & 1.6 & 1 \\
\hline 3 & Carolina & Radio sonde & 1.8 & 1 \\
\hline 4 & Floriano & Radio sonde & 1.5 & 1 \\
\hline 5 & B.J.da Lapa & Radio sonde & 1.4 & 1 \\
\hline 6 & Recife & Radio sonde & 1.7 & 1 \\
\hline 7 & S. Luiz & Radio sonde & 1.7 & 1 \\
\hline \multirow{2}{*}{8} & \multirow{2}{*}{ Petrolina } & Radio sonde & 1.4 & 1 \\
\hline & & Refractometer & 2.2 & $<0.3$ \\
\hline 9 & Trindade & Radio sonde & 3.6 & 0.5 \\
\hline \multirow{2}{*}{10} & \multirow{2}{*}{ Belém } & Radio sonde & 2.9 & 1 \\
\hline & & Refractometer & 2 & 0.3 \\
\hline \multirow{2}{*}{11} & \multirow{2}{*}{ Rio de Janeiro } & Radio sonde & 2.1 & 0.9 \\
\hline & & Refractometer & 2.5 & $<0.5$ \\
\hline \multirow{2}{*}{12} & \multirow{2}{*}{ Campo Grande } & Radio sonde & 1.3 & 0.9 \\
\hline & & Refractometer & 2.5 & 0.6 \\
\hline 13 & Curitiba & Radio sonde & 1.5 & 0.8 \\
\hline 14 & Jiparaná & Refractometer & 3.6 & 0.5 \\
\hline 15 & Cáceres & Refractometer & 2.3 & $<0.5$ \\
\hline 16 & Goiania & Refractometer & 2.1 & 0.4 \\
\hline
\end{tabular}

Table 4 - Measured values of $K_{\min }$ and $K_{\text {med }}$

\section{Multipath Fading Measurements}

Examples of cumulative distributions of single frequency multipath fading from continuous one year records of AGC level in 12 line-of-sight analog microwave links are shown in Figure 14. The link characteristics are described in Table 5.

In almost all cases, the measured distributions were well fitted by conditional Rayleigh distributions, allowing the determination of the multipath fading occurrence factor $r$. This parameter is related to geoclimatic parameter $K$ defined by the ITU-R[2]:

$$
K=\frac{r}{d^{3,3} \cdot f\left(0,93 \cdot\left(1+\left|\varepsilon_{p}\right|\right)^{-1,1} \cdot \varphi^{-1,2}\right.}
$$


where $d$ is the path length in $\mathrm{km}, f$ the frequency in $\mathrm{GHz}, \varepsilon_{p}$ and $\varphi$ in mradians are, respectively, the path inclination and the grazing angle, as defined in reference [2]. The values of $G$ obtained are also shown in Table 5 .

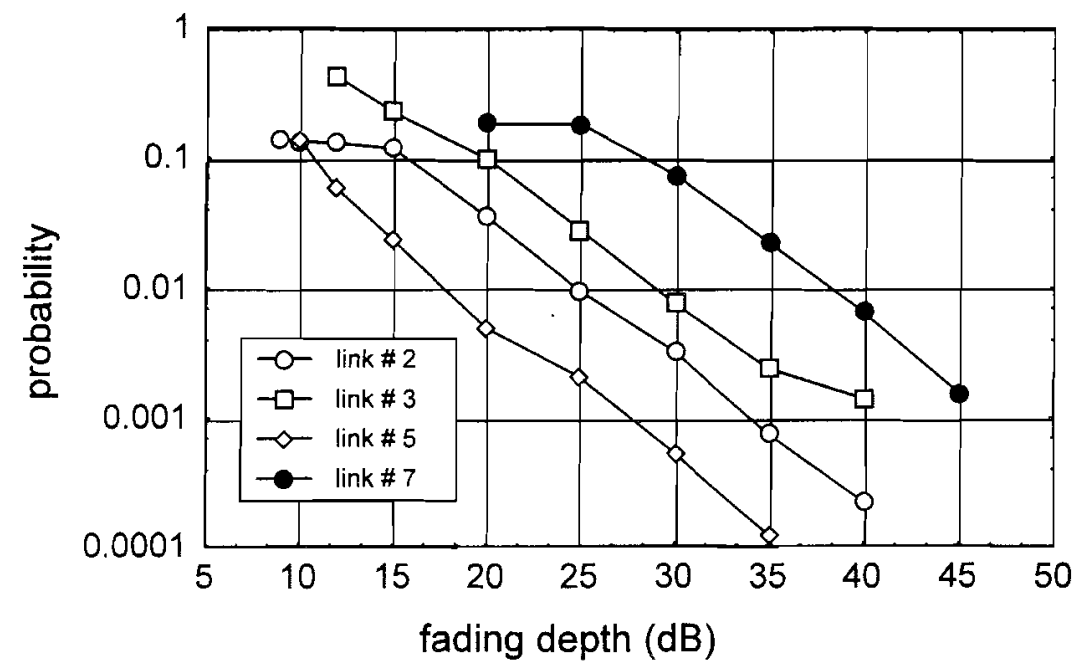

Figure 14 - Cumulative distributions of single frequency multipath fading

\begin{tabular}{c|c|c|c|c|c|c|c}
\hline$\#$ & Latitude & Longitude & $\begin{array}{c}\text { Path lenght } \\
(\mathbf{K m})\end{array}$ & $\begin{array}{c}\text { Frequency } \\
(\mathbf{G H z})\end{array}$ & $\mathbf{r}(\%)$ & $\mathbf{K}(\%)$ & $\begin{array}{c}<\tau \\
(\mathbf{n s})\end{array}$ \\
\hline 1 & $23^{\circ} 22^{\prime} \mathrm{S}$ & $45^{\circ} 32^{\prime} \mathrm{W}$ & 44 & 6.3 & 0.9 & n. a. & 1.2 \\
\hline 2 & $25^{\circ} 15^{\prime} \mathrm{S}$ & $49^{\circ} 09^{\prime} \mathrm{W}$ & 40.2 & 6.3 & 4.4 & $22 \times 10^{-5}$ & 0.6 \\
\hline 3 & $23^{\circ} 11^{\prime} \mathrm{S}$ & $51^{\circ} 05^{\prime} \mathrm{W}$ & 54.5 & 7.5 & 9.3 & $4 \times 10^{-5}$ & 0.9 \\
\hline 4 & $23^{\circ} 00^{\prime} \mathrm{S}$ & $47^{\circ} 31^{\prime} \mathrm{W}$ & 57.5 & 6.3 & 11 & n. a. & 0.5 \\
\hline 5 & $25^{\circ} 19^{\prime} \mathrm{S}$ & $48^{\circ} 18^{\prime} \mathrm{W}$ & 46.6 & 7.7 & 0.6 & $19 \times 10^{-5}$ & n.a. \\
\hline 6 & $25^{\circ} 01^{\prime} \mathrm{S}$ & $50^{\circ} 05^{\prime} \mathrm{W}$ & 68 & 7.5 & 25 & $2.7 \times 10^{-5}$ & 1.4 \\
\hline 7 & $23^{\circ} 17^{\prime} \mathrm{S}$ & $43^{\circ} 21^{\prime} \mathrm{W}$ & 57.5 & 4 & 3.7 & n.a. & 0.5 \\
\hline 8 & $22^{\circ} 13^{\prime} \mathrm{S}$ & $54^{\circ} 48^{\prime} \mathrm{W}$ & 57.8 & 4 & 13 & $7.3 \times 10^{-5}$ & 0.7 \\
\hline 9 & $18^{\circ} 43^{\prime} \mathrm{S}$ & $47^{\circ} 29^{\prime} \mathrm{W}$ & 65.2 & 7.5 & 6.2 & $3.6 \times 10^{-5}$ & 0.8 \\
\hline 10 & $20^{\circ} 09^{\prime} \mathrm{S}$ & $44^{\circ} 54^{\prime} \mathrm{W}$ & 46 & 7.5 & 2 & $3.2 \times 10^{-5}$ & 0.1 \\
\hline 11 & $19^{\circ} 10^{\prime} \mathrm{S}$ & $41^{\circ} 52^{\prime} \mathrm{W}$ & 57.5 & 7.5 & 12 & $17 \times 10^{-5}$ & 1.3 \\
\hline 12 & $21^{\circ} 33^{\prime} \mathrm{S}$ & $45^{\circ} 26^{\prime} \mathrm{W}$ & 58.5 & 7.5 & 1.5 & $2.7 \times 10^{-5}$ & 0.3 \\
\hline
\end{tabular}

Table 5 - Characteristics of the links and multipath fading measurements results 
In addition to the AGC level, the continuity pilot level was detected and continuously recorded in the links described in Table 5. During the occurrence of multipath fading enhancements in the pilot level are observed that, together with the AGC level can be used[6] to provide estimates for the parameters of the multipath channel transfer function:

$$
H(f)=1+b \cdot e^{22 \pi\left(f-f_{c}\right) \tau}
$$

Histograms of the maximum fade depth $(\lambda=1-b)$ relative delay $\tau$ were obtained from the measured data. The histograms of the relative delay are, in almost all cases, well fitted by exponential density function:

$$
p_{\tau}(\tau)=\frac{1}{\langle\tau\rangle} \cdot e^{-\frac{\tau}{\langle\tau\rangle}}, \tau \geq 0
$$

The values of the average relative delay $\langle\tau\rangle$, obtained for several links, are shown in Table 5 .

Strong correlation between the path length $d(\mathrm{~km})$ and inclination $\varepsilon_{p}(\mathrm{mrad})$ was observed. An expression for estimating the average delay as a function of these link parameters was derived:

$$
<\tau>(n s)=0.05 \cdot d^{0,87} \cdot e^{-0,25|\varepsilon p|}
$$

\section{Conclusion}

A review of the results of propagation measurements' campaigns carried out in Brazil in the last 15 years has been presented in this paper. These results are being used to develop and test propagation prediction methods for tropical and equatorial climates, and have also direct application in the design of radiocommunication system in such regions.

\section{References}

[1] CCIR Recommendation 837, RPN Series, Geneva 1992

[2] CCIR Recommendation 5304, RPN Series, Geneva 1992 
[3] Migliora CGS, Pontes MS and Silva Mello LAR, Elec Lett, 26 (19) (1990).

[4] Hodge DB, Radio Science, 17 (6) (1982), 1393.

[5] Dhein NR, Pontes MS and Silva Mello LAR, "Statistical Behaviour of Refractivity Gradient in the Tropics", Proceedings of ICAP'93, UK, March 1993.

[6] Taylor D P and Shaf1 M 1983, A Simple Method for Estimating Multipath Fade Parameters", IEEE Trans. Comm., COM-31.

Luiz Alencar Reis da Silva Mello is Associate Professor at the Catholic University of Rio de Janeiro. He received the degree of Electrical Engineer (Telecommunications) and the M. Sc. and D. Sc. degrees in Electrical Engineering from PUC/RJ in 1975, 1977 and 1987, respectively. He has been with the Center of Telecommunication Studies of the Catholic University of Rio de Janeiro (CETUC-PUC/Rio) since 1977. In 1984 and 1985 he worked on millimeter wave propagation as Visiting Researcher at University College London. At PUC-Rio he has been Administrative Coordinator of the Center for Sciences and Technology from 1988 to 1991, Vice-Dean of the Center for Sciences and Technology 1989 to 1991 and is presently Coordinator of Academic Planning. At CETUC, he was Coordinator of Undergraduate Studies from 1979 to 1981 and is Head of the Radio Propagation Group since 1987. He is involved in teaching and research activities in the area of radiowave propagation. His current research interests are in radiowave propagation in the troposphere and analog and digital radio systems performance.

Marlene Sabino Pontes is Associate Professor at the Catholic University of Rio de Janeiro. She received the degree of Electrical Enginner from Universidade Federal de Juiz de Fora in 1969 and the M. Sc. degree in Electrical Enginnering from PUC/RJ in 1972. She has been with the Center of Telecommunication Studies of the Catholic University of Rio de Janeiro (CETUC-PUC/Rio) since 1971. In 1973 she worked on radiometeorology as visiting researcher at the Centre National d' Études des Télécommunications (CNET) at Issy-les-Moulineaux, France, and in the period 1979 to 1981, she was a staff engineer at the Propagation Studies Department of COMSAT Laboraties, U.S.A., working in the areas of microwave propagation in the troposphere and in the ionosphere. At CETUC, she was Coordinator of Undergraduate Studies in 1979, Vice-Director from 1982 to 1984, Head of the Radio Propagation Group in the period 1984 to 1985 and is Director since 1984. She is involved in teaching and research activities in the area of radiowave propagation. Her current research interests are in applied electromagnetics, wave propagation in non-ionized media and radiometeorology. 
Ney Roberto Dhein is Assistant Professor at the Catholic University of Rio de Janeiro. He received the degree of Electrical Engineer (Electronics) from Universidade Federal do Rio Grande do Sul in 1972 and the M. Sc. degree in Electrical Engineering from PUC/RJ in 1975. He has been with the Center of Telecommunication Studies of the Catholic University of Rio de Janeiro (CETUC-PUC/Rio) since 1975. In 1978 he worked on radiometeorology as research assistant at the Institute for Telecommunications Sciences at Boulder, U.S.A. At CETUC he elaborated the courses "Improvement Techniques in Radio Links" and "Digital Radio Systems" for the Center of Development and Technology of the National Institute of Telecommunicatiions in 1986 . He developed the "Refractometer", an instrument for direct measurement of atmospheric refractivity, that was patented in 1984 . He is presently involved in teaching and research activities in the area of radiowave propagation. His current research interests are in radiowave propagation in the troposphere and analog and digital radio systems.

Cláudio Monteiro Einloft is Assistant Professor at the Catholic University of Rio de Janeiro. He received the degree of Electrical Engineer (Electronics) from Universidade Federal do Rio Grande do Sul in 1971 and the M. Sc. degree in Electrical engineering from PUC/RJ in 1974. He has been with the Center of Telecommunication Studies of the Catholic University of Rio de Janeiro (CETUC-PUC/Rio) since 1973. In 1974 he worked on radiometeorology as a visiting researcher at the Centre National d'Études des Télécommunications (CNET) at Issy-les-Moulineaux, France. At CETUC, he elaborated the courses "Analog Radio Transmission Systems" for the Federal Railroad Company in 1982 and "Microwave Systems" for the Center of Development and Technology of the National Institute of Telecommunications 1986. He is presently Coordinator of Undergraduate Studies in Telecommunications and is involved in teaching and research activities in the area of radiowave propagation. His current research interests are in radiowave propagation in the troposphere and analog and digital radio systems. 